\title{
Feasibility of Integrating Huishan Clay Figurine into Brand Visual Design in Scenic Areas
}

\author{
Yicheng $\mathrm{Xu}^{1, *}$ \\ ${ }^{1}$ Wuhan Textile University, Wuhan, Hubei 430000, China \\ ${ }^{*}$ Corresponding author. Email: 13376202739@163.com

\begin{abstract}
Brand design in scenic areas, originally an essential means to attract tourists, lacks flexibility and appeal because of the influence of stereotypes. The failure to utilize their own intellectual property (IP) and to inherit and develop traditional culture leads to weakness in design and aesthetics, thus not attracting tourists. The application of Huishan clay figurine into the brand design in scenic areas not only increases the appeal and charm of the scenic spot, but also enriches subsequent cultural and creative design. Taking the intangible cultural heritage Huishan clay figurine and Huishan ancient town where it locates as an example, this paper explores the methods to integrate brand design into the scenic spot from two aspects of innovation and application, so as to apply Huishan clay figurine into brand design to better publicize the scenic spot and inherit culture.
\end{abstract}

Keywords: Brand design, Huishan clay figurine, Intellectual property (IP).

\section{INTRODUCTION}

IP image serves as an important part of a brand. A good IP can not only bring widespread popularity, but also create endless value. Wellknown IPs including Mickey, Goku, and Kumamoto are highly recognizable, widely employed in daily consumer products covering souvenirs, clothing, and electronic products. Either designed by designers or developed with timehonored background, they all enjoy high degree of identification and popularity. Therefore, the success of IP image hinges on not only its ability to tell a fascinating story, but public recognition on related factors including appearance, connotation, and background. Huishan clay figurine, a famous intangible cultural heritage, has won public favor for thousands of years, and can be found in many film and television. Its application into Huishan scenic area is feasible given the former's solid mass base, which innovates intangible heritage items using cultural identity, thus realizing the selfinnovation of IP image.

\section{AN OVERVIEW OF HUISHAN CLAY FIGURINE IP DESIGN}

Huishan clay figurine, an intangible cultural heritage of Wuxi City, Jiangsu Province, boasts a history of more than 400 years. The image is cute and vivid, winning the favor of both adults and children. However, a systematic brand has not yet formed. If the entire scenic spot is a person, the brand is his name and appearance, which are often published on websites and newspapers. Huishan scenic area which boasts such a unique IP is required to make good use of the IP for brand design. Huishan clay figurine can be employed to design widely accepted images because of their cuteness. Brand visual design of the scenic spot represents the overall image of the scenic spot, including items such as a signage system. It serves as the "spokesperson" of the scenic spot for tourists, which help them to clarify the distribution, highlights, cultural atmosphere and allusions of the scenic spot. As a result, IP matters the overall image of the scenic spot. A favorable IP better advertises the spot through booming social platforms, thus attracting more tourists. At the same time, such IP can also be taken to develop games using multimedia technology that can be played on phones, enhancing the connectivity and interaction 
between the scenic spot and the audience, and resulting in invaluable benefits.

\section{DEVELOPMENT STATUS OF HUISHAN SCENIC AREA}

Huishan scenic area including Huishan ancient town and Huishan tourist attraction is characterized by unique geographical location, beautiful natural environment, and densely distributed ancient ancestral halls. It is the only block with wellpreserved old neighborhood style in Wuxi. In June 2006, the ancient ancestral halls of Huishan ancient town was approved as a national key cultural relic protection unit by the State Council. Huishan ancient town has been included in the World Cultural Heritage Preliminary List. Huishan ancient town relies on ancient ancestral halls, connecting Erquan Jichang Garden, Huishan Town, Huishan Zhijie Street, Hengjie Street and Huishan Clay Figure Museum. Its overall planning and development and construction highlight history and culture. The main highlights of Huishan ancient town range from Hengjie Street, Huishan Zhijie
Street to east of Baoshan Bridge, covering an area of about 150,000 square meters. The reintegration and environmental management of various buildings in the area are conducted based on the ancient ancestral halls of Huishan ancient town to restore the traditional style of the original Huishan ancient town. Two traditional ancient streets along the Huishanbang, and two lanes and Huishanbang water channel are set, thus building the Huishan ancient scenery area extending from the east side of Jichang Garden to Huangbutun.

\subsection{Analysis of Cultural Characteristics of Huishan Scenic Area}

Huishan scenic area that is divided into two parts including Xihui Park and Huishan ancient town is backed by Huishan Mountain, boasting lush mountains and lucid waters. Huishan ancient town is known for its ancestral halls, the largest group of ancestral halls in China. Xihui Park also includes many historical sites. In recent years, the scenic spot has succeeded in creating an AAAAA-level scenic spot and continues to be repaired, striding towards the road to world heritage. ("Table 1")

Table 1. The overall folk tourism resources in the scenic area

\begin{tabular}{|l|l|l|l|l|}
\hline & $\begin{array}{l}\text { Places of historic figures } \\
\text { and cultural heritage }\end{array}$ & Natural landscape & Folk activity & Specialty food \\
\hline Xihui Park & Jichang Garden & Huanggong Jian & Huishan fair & Huishan pastry \\
\hline & $\begin{array}{l}\text { The second spring in the } \\
\text { world }\end{array}$ & Yugong Valley & $\begin{array}{l}\text { Ring the bell for good } \\
\text { luck }\end{array}$ & Beancurd jelly \\
\hline & Huishan temple & Bayin Jian & Fengyulong & Dumpling \\
\hline Huishan ancient town & Yangoufang Ci & Huishan Park & & Yinsi noodles \\
\hline & Liugeng cottage & & & \\
\hline & Museum of clay figurine & & & \\
\hline
\end{tabular}

\subsection{Status Quo and Shortcomings of Brand Building in Huishan Scenic Area}

\subsubsection{Unsystematic Brand Design}

No other design except logo can be found in the scenic area, let alone signage system and cultural and creative design, which fails to highlight the features of the scenic area. The abundant tourism resources of Huishan scenic area are not utilized. As a result, tourists from afar just make a circle around the scenic area, unable to understand the deeper connotation. What's worse, support from a strong IP lacks. Field research reveals that despite the rich tourism resources in Huishan scenic area, many tourists only come to watch the natural landscape, while local tourists just treat it as a place to relax with tea and exercise in the morning. There shortage of clear publicity orientation and unique cultural and creative tourism products make it worse. Except for a few bookstores, you can only see the products that can be seen everywhere in other scenic spots here.

\subsubsection{Imperfect Signage System}

No precise signage system can be found. Except for the map at the door, there are only some general guidance signs. Existing signage system of the whole scenic spot has not been completely unified. Tourists have trouble in deciding their route, either climbing Huishan first, and then enter Huishan ancient town via Xihui Park, or strolling from Huishan ancient town first. The distance between those attractions is very long, requiring much for their physical strength and interest. A complete signage system can help tourists made such 
decisions and avoid wasting energy because of the wrong path.

\subsubsection{Dominace of Middle-aged and Elderly Group, and Failure to Attract the Young}

Huishan has long been a place for Wuxi citizens to relax. There are elderly groups exercising, drinking tea, and gathering, while younger groups are relatively few. However, the introduction of IP in scenic spots and the creation of cultural and creative products facilitate the formation of Internet celebrity economy, thus attracting young people. The popularity of ancient costumes such as Hanfu in recent years helps to utilize the ancient style of Huishan scenic area. According to existing survey, many film and television dramas have been filmed here. It is feasible to employ propaganda methods such as the scene of a certain drama to create new hotspots, attracting young people, which helps to solve the bottleneck in development.

\subsubsection{Failure to Achieve Comprehensive Development in Cultural Inheritance}

Clan kinship is supposed to be a vital theme of the scenic area as it enjoys the largest and most concentrated ancient ancestral halls in the world. However, it's seldom mentioned and many locals know nothing about the selling point, let alone tourists from afar. Tourists coming here are more familiar with the Second Spring in the World, Jichang Garden and so on. Culture needs to be inherited, and no culture can be ignored. "Clan kinship" is a gene carved into the bones of Chinese people. The speech of the general secretary should be kept in mind and practiced to strengthen cultural self-confidence. In addition to cultural inheritance, innovations should also be encouraged, and more methods should be employed for promotion. IP, a good selling point, can be adopted to design a series of images and comic stories concerning the ancestral halls, so that visitors can understand the stories and indirectly inherit culture.

\section{THE APPROACHES TO PRESENT THE IP OF HUISHAN CLAY FIGURINE}

Huishan clay figurine, a well-known image in China, can be presented in characters, animals, dramas, etc. They are objects that help people understand beauty from the visual and tactile aspects. However, no specific brand concerning
Huishan clay figurine have been set up, and their applications are mixed. IP mirrors the overall image of the scenic spot. The famous scenic spots, specialties and so on should be refined within, so that people will think of Huishan scenic area as soon as they see this IP. A complete IP can be reflected in the following approaches:

\subsection{Generalization and Abstraction}

Generalization and abstraction refers to turn a concrete thing into a non-concrete image. Like the works of abstract painters such as Picasso, it focuses more on expressing the inner quality and spirit, and a major advantage of abstraction is that it can be accepted by people more quickly. For example, the IP of Huishan clay figurine. Since the common clay figures are boys and girls, it is possible to abstract this well-known image to make it more interesting. Some decorations such as wall painting in scenic spots will greatly increase the curiosity of tourists.

\subsection{Exaggeration and Amplification}

Exaggeration is a way to exaggerate or reduce the image, characteristics, function, and degree of things in order to achieve a certain expression effect. Contrasting colors and materials can be utilized boldly. The Huishan clay figurine is originally employed to express people's yearning for a better life. Such meaning can be reflected more clearly, some signs of the scenic spot can be added, and blend them together to express the joy of the scenic spot in an exaggerated way.

\subsection{Information Technology}

The development of the times makes it more effective to advertise through information technology. Web Celebrity Marked are popular among young people. However, many web celebrity scenic spots lack stamina. Therefore, after a certain achievement, information technology should be used to consolidate the position instead of making gimmicks all the time, so as to make tourists feel content. The IP of Huishan clay figurine can be used for secondary creation to develop small games and small programs that can be downloaded on mobile phones and promoted on major social apps, so that visitors can feel the charm of the scenic spot anytime and anywhere, strengthen connectivity, and achieve the goal of attracting audience. 


\section{SUGGESTIONS FOR THE APPLICATION OF HUISHAN CLAY FIGURINE IP DESIGN IN THE BRAND OF HUISHAN SCENIC AREA}

\subsection{Learning from Successful Cases of Similar IP}

The successful case of Disneyland must be mentioned when it comes to the application of IP in scenic brands. Disney has many familiar IPs, such as Mickey Mouse, Cinderella, Snow White and so on. Walking into Shanghai Disneyland, Mickey's head silhouette can be found behind the five characters of Disneyland at the main entrance. In addition, Mickey's colorful eggs can be seen everywhere in Disneyland, such as above the gate of the fantasy fairytale castle, the toilet tiles in Treasure Bay, the stone masonry at the toilet door in Dream World, the murals in the Budalong market, the windows of a small building in Disney Town, the iron gate at the entrance of the second ticket gate, the garden of the Queen of Hearts, the glass roof of the entrance ticket gate, the decoration of Snow White Castle, the skylight of Snow White Castle, the wooden decoration of the walls of Manyue Xuan (restaurant), the bell tower at the entrance, the entrance floor of Tomorrow land, etc. It proves that a good IP should be applied to the extreme in this way, which also explains the success of Disney. Such fairy tales are the key to tourists' interest. Although Huishan clay figurine do not have such fairy tales, they have folklore spread by word of mouth. This can also be utilized to arouse public curiosity. The Chinese culture is extensive and profound. The IP of Huishan clay figurine can be adopted to design signage system, LOGO, mascots, etc., and develop related minigames, and even produce related animations. Like Disneyland, the IP should be integrated into the scenic area deeply to better the experience of tourists and create a perfect "Huishan scenic area" brand.

\subsection{Improving the Recognition of Huishan Clay Figurine IP}

IP needs to be innovation-driven if it wants to be recognized and accepted by the mainstream. Survey reveals that mainstream social networking sites such as Bilibili and Douyin have reached tens of millions of daily hits, which can be explained by a large number of users. Many young people love animation. Huishan clay figurine has been loved for their cute images in the past. Now they can be redesigned into brand-new animation images for audiences to accept. Interaction with same type of games such as domestic mobile game "Onmyoji" can be carried out. For example, the image of "Dharma" can be replaced with Huishan clay figurine, making players be familiar with such image, indirectly broadening the audience of Huishan clay figurine and making the scenic spot a "marked place" for players.

Design is equally important as innovation in publicity. "People-oriented" design should be emphasized to better serve tourists and users. The design of Huishan clay figurine can be conducted from five senses including image, sound, smell, taste, and touch. No more details on image. In terms of voice, famous actors can be invited to dub IP; perfumes and fragrances in the image of Huishan clay figurines can be created as for smell; Huishan pastry can be made in the shape of Huishan clay figurine, or its packaging can be designed with the IP as for taste; and classrooms for making clay figurines can be carried out regularly to increase the participation of tourists and enhance tourists' intimacy towards the scenic spot as for touch. Such humanized design can resonate visitors and increase their sense of identity with IP.

\subsection{Strengthening the Promotion and Publicity of Huishan Clay Figurine IP}

The era of information requires adaptation to the changes of the times and courage in innovation instead of rigidly adhering to stereotypes. Mobile phones are the tools mostly used in daily life. People like to share their daily lives on major social software, and various advertisements abound on the Internet. As a vital tool for publicity in scenic spots, IP can better promote the scenic area by placing advertisements on these social platforms and interacting with netizens. Such examples can be found in real life, such as the Yutu lunar rover, which opened Weibo and frequently updated the daily routine of the lunar rover, popularizing science and aerospace knowledge, and gaining a group of fans. The IP of Huishan clay figurine can be implanted in interesting games developed with software, which offers fun and leisure for people. Over time, people will default to this image, achieving the effect of publicity. In addition, IP can be widely used in public transportation and subway station signs, social platforms, and TV 
advertisements to increase passenger flow and increase popularity.

\section{CONCLUSION}

IP image is the selling point of the brand. Huishan clay figurine can be adopted as the IP of Huishan scenic area to build signage system, slogans, tourist routes, etc. making it an internationally renowned scenic spot. The approach to design popular mascot into a modern IP is one of the more acceptable methods for young people inside and outside China, which better reflect the excellent tourism resources of Huishan scenic area and attract more global tourists, thus inheriting and innovating traditional culture.

\section{AUTHORS' CONTRIBUTIONS}

This paper is independently completed by Yicheng Xu.

\section{REFERENCES}

[1] Ding Suchuan. Research on Local Brand Design Based on Nanjing Urban Culture [J/OL]. Packaging Engineering:1-16 [202101-12]. (in Chinese)

[2] Hao Wenjuan. Application of Guizhou ethnic minority Miao and Dong Cultures in the design of tourism cultural and creative brand [J]. Tourism Overview, 2020(21): 72-74. (in Chinese)

[3] Yao Yao. The feasibility analysis of animation IP design entering the tourist attraction identification system [J]. Journal of Beijing Institute of Graphic Communication, 2020, 28(02): 74-76+83. (in Chinese)

[4] Wu Keying. Analysis of the Artistic Characteristics of the Clay Figurine Children's Figure in Wuxi Huishan [J]. Shanghai Arts \& Crafts, 2020(04): 100-103. (in Chinese)

[5] Chen Yiting, Pan Chunyu. The Design Extension of Huishan Clay Figure Color in Tourist Souvenirs During the Republic of China [J]. Design, 2020, 33(09): 17-19. (in Chinese)

[6] Liu Xiaoyu. Using IP to build a brand-the IP image design of Guangzhou Little Monster Art Camp [J]. The Food Industry, 2020, 41(12): 436. (in Chinese)
[7] An Wenyue. Research on board game design based on the cultural image of the ancient town of Huishan [J]. MING (Attitude), 2019(11): 16+18. (in Chinese) 